\title{
Microstructural Evolution of NF709 (20Cr-25Ni-1.5MoNbTiN) under Neutron Irradiation
}

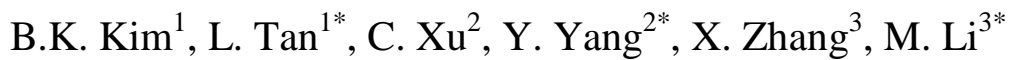 \\ ${ }^{1}$ Oak Ridge National Laboratory, Oak Ridge, TN 37831 \\ ${ }^{2}$ University of Florida, Gainesville, FL 32611 \\ 3 Argonne National Laboratory, Lemont, IL 60439 \\ *Corresponding Authors: tanl@ornl.gov (L. Tan); yongyang@ufl.edu (Y. Yang); mli@anl.gov \\ (M. Li)
}

\begin{abstract}
Because of its superior creep and corrosion resistance as compared with general austenitic stainless steels, NF709 has emerged as a candidate structural material for advanced nuclear reactors. To obtain fundamental information about the radiation resistance of this material, this study examined the microstructural evolution of NF709 subjected to neutron irradiation to 3 displacements per atom at $500^{\circ} \mathrm{C}$. Transmission electron microscopy, scanning electron microscopy, and high-energy x-ray diffraction were employed to characterize radiation-induced segregation, Frank loops, voids, as well as the formation and reduction of precipitates. Radiation hardening of $\sim 76 \%$ was estimated by nanoindentation, approximately consistent with the calculation according to the dispersed barrier-hardening model, suggesting Frank loops as the primary hardening source.
\end{abstract}

\section{Introduction}

Continuous efforts to develop advanced heat-resistant austenitic stainless steel have led to the commercialization of several new alloys, e.g., Sanicro 25 (Sandvik, Sweden), HR3C (Sumitomo Metal, Japan), DMV 310N (Salzgitter Mannesmann, Germany), and NF709 (Nippon Steel, Japan). NF709 was developed based on Nb/Ti-stabilized 20Cr-25Ni stainless steel in the mid1980s for ultra-supercritical fossil power plants [1]. It has shown superior performance at elevated temperatures in terms of creep and corrosion resistance. Currently, NF709 (ASTM A213 TP310MoCbN and UNS No. S31025) is being investigated as a candidate structural material for sodium-cooled fast reactor and other forms of advanced reactors.

Unlike conventional solid solution austenitic stainless steels, NF709 develops a variety of precipitates during aging at different temperatures. Precipitation of a large amount of carbides at grain boundaries and adjacent areas was observed after aging at $700^{\circ} \mathrm{C}$, which resulted in a decrease in Charpy impact toughness to 30-40 J after 1,000 h aging [2]. Similarly, aging at 750 and $800^{\circ} \mathrm{C}$ yielded $\mathrm{M}_{23} \mathrm{C}_{6}\left(\mathrm{M}\right.$ : mainly $\mathrm{Cr}$ ) precipitation (after a short time) and $\mathrm{Cr}_{3} \mathrm{Ni}_{2} \mathrm{SiX}_{(\mathrm{X}}$ : mainly $\mathrm{N}$ ) precipitation (after longer aging) at grain boundaries as well as twin boundaries, together with the formation of $\mathrm{Z}$-phase $(\mathrm{CrNbN})$ due to conversion of pre-existing $\mathrm{NbN}$ particles in the solution-annealed NF709 [3]. Additionally, a large amount of G-phase $\left(\mathrm{Ni}_{16} \mathrm{Nb}_{6} \mathrm{Si}_{7}\right)$ was observed in $\mathrm{Nb}$-stabilized $20 \mathrm{Cr}-25 \mathrm{Ni}$ stainless steel during creep at 750 and $850^{\circ} \mathrm{C}$; it was believed to have formed from pre-existing $\mathrm{NbC}$ particles as a result of the segregation of silicon [4]. Later work on the same type of steel also confirmed the transformation of $\mathrm{Nb}(\mathrm{C}, \mathrm{N})$ to the G- 
phase even at $500^{\circ} \mathrm{C}$ [5]. The formation and/or transformation of precipitates altered the properties of NF709 and Nb-stabilized $20 \mathrm{Cr}-25 \mathrm{Ni}$ at the testing temperatures.

Reports about radiation effects on this class of alloys, primarily related to $\mathrm{Nb}$ /Ti-stabilized 20Cr-25Ni alloys, were conducted during 1960s-1990s because of their use as a fuel-cladding material for advanced gas-cooled reactors. Radiation-induced (Ni,Nb,Si)-rich and (Ni,Si)-rich precipitates were observed in the alloys irradiated at $440-640^{\circ} \mathrm{C}$ and $360-480^{\circ} \mathrm{C}$, respectively [6]. Generally, radiation-induced hardening was observed in the steels, accompanied by significant reductions in ductility, causing fracture characteristics to change from transgranular (unirradiated) to intergranular (irradiated) at irradiation temperatures of $550-900^{\circ} \mathrm{C}[7,8]$. Similar to the results for general austenitic stainless steels, radiation-induced segregation (RIS) of Cr depletion and $\mathrm{Ni}$ enrichment was observed at the grain boundaries of a Fe-20Cr-24Ni model alloy under proton irradiation to 3 displacements per atom (dpa) at $200-600^{\circ} \mathrm{C}$. It exhibited maximum $\mathrm{Cr}$ depletion (to $\sim 8.7 \mathrm{wt} \%$ ) and $\mathrm{Ni}$ enrichment (to $\sim 28.6 \mathrm{wt} \%$ ) at $\sim 500^{\circ} \mathrm{C}$ and $0.5 \mathrm{dpa}$ [9]. The segregation was slightly aggravated with increasing dpa. Such significant RIS at grain boundaries may be somewhat mitigated in complex alloys like NF709 because of the increase in defect recombination sites in the matrix [10].

Recent exploration of new alloys for advanced nuclear reactors has brought NF709 to researchers' attention for radiation resistance assessment. This paper reports radiation-induced microstructural evolution, including Frank loops, voids, precipitates, and RIS, as well as hardening of NF709 subjected to neutron irradiation to $3 \mathrm{dpa}$ at $500^{\circ} \mathrm{C}$.

\section{Experimental}

The tested NF709 was supplied by Nippon Steel. As measured by Evans Analytical Group, its composition was $0.0014 \mathrm{~B}, 0.076 \mathrm{C}, 0.11 \mathrm{~N}, 0.42 \mathrm{Si}, 0.016 \mathrm{P}, 0.0001 \mathrm{~S}, 20.5 \mathrm{Cr}, 0.76 \mathrm{Mn}, 25.7 \mathrm{Ni}$, $0.32 \mathrm{Nb}, 1.52 \mathrm{Mo}, 0.033 \mathrm{Ti}, 0.365 \mathrm{Cu}$, and the balance $\mathrm{Fe}$ in weight percentage. The available record indicates that the material was hot-rolled to a $12.7 \mathrm{~mm}$ thick plate, followed by annealing in air at $1107^{\circ} \mathrm{C}$ for $20 \mathrm{~min}$. and water quenching. Samples of NF709 were part of the pilot neutron irradiation campaign using the Advanced Test Reactor National Scientific User Facility at Idaho National Laboratory [11]. Two types of samples - tensile $(16 \times 4 \times 1 \mathrm{~mm})$ and discs of $3 \mathrm{~mm}$ diameter and $\sim 0.2 \mathrm{~mm}$ thickness - were irradiated at 400,500 , and $700^{\circ} \mathrm{C}$ to 3 and 6 dpa. This paper reports the analysis results for the discs irradiated to $3 \mathrm{dpa}$ at $500^{\circ} \mathrm{C}$.

The irradiated $\left(3 \mathrm{dpa} / 500^{\circ} \mathrm{C}\right)$ sample, as well as an archived nonirradiated (AR) sample, were mechanically ground and polished to a mirror finish with colloidal silica. An Agilent Nano Indentor G200 was used for hardness measurements at room temperature. A matrix of up to 80 indentations was produced on each sample to produce good statistical indentation results. The microstructures of the samples were characterized using scanning electron microscopy (SEM: JEOL 6500 field-emission gun [FEG]), energy-dispersive $\mathrm{x}$-ray spectroscopy (EDS), transmission electron microscopy (TEM: FEI CM200 FEG at $200 \mathrm{kV}$ ) in the conventional and scanning (STEM) modes, and high-energy x-ray diffraction (XRD) using the Advanced Photon Source (APS) at Argonne National Laboratory. TEM specimens were prepared using focused ion beam (FIB: FEI Quanta 3D dual beam SEM/FIB). Low voltage (e.g., $2 \mathrm{keV}$ ) ion-beam cleaning 
was applied to the specimens as a final step to reduce or eliminate FIB-induced artifacts. The local TEM specimen thickness for volumetric analysis was estimated using convergent beam electron diffraction method. Grain boundary chemistry was analyzed using STEM-EDS.

\section{Results and discussion}

\subsection{Unirradiated archive specimen}

The AR sample was characterized using back-scattered electron (BSE) imaging, as shown in Fig. 1. The BSE images show dominant equiaxial grains $(26.78 \pm 3.16 \mu \mathrm{m})$ with well-developed annealing twins at different crystallographic orientation contrasts, together with some nonrecrystallized large grains (e.g., lower-right corner of Fig. 1a). The equiaxial grain size was slightly smaller than the specified grain size limit of $\geq 31.8 \mu \mathrm{m}$ (i.e., ASTM Grain Size No. $\leq 7$ ) for ASTM A213 TP310MoCbN, which may have been the result of using a slightly lower solution temperature $\left(1107^{\circ} \mathrm{C}\right)$ than the specified $\geq 1150^{\circ} \mathrm{C}$ [12]. A higher-magnification image (Fig. 1b) revealed many bright, fine particles $(<\sim 100 \mathrm{~nm})$ with a few coarse particles $(\sim 0.4-10$ $\mu \mathrm{m})$, together with a few dark fine particles $(<\sim 4 \mu \mathrm{m})$. The bright and dark particles were identified as Nb-rich and Ti-rich particles by EDS analyses.
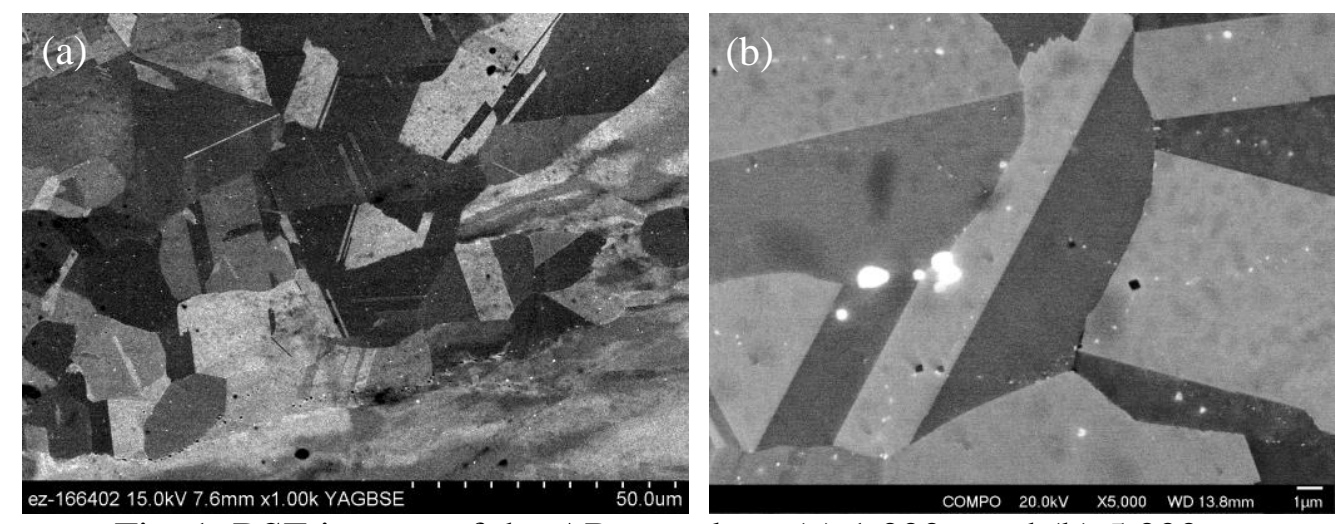

Fig. 1. BSE images of the AR sample at (a) $1,000 \times$ and (b) 5,000×.

Two groups of precipitates (coarse and fine), randomly distributed in the matrix as well as in the grain or subgrain boundaries, were observed in the AR sample as shown in the bright-field (BF) TEM image of Fig. 2a. A few stringers of ultrafine particles are also shown in Fig. 2a. The sizes of the coarse particles $(\sim 0.4 \mu \mathrm{m})$ and fine particles $(\sim 20-100 \mathrm{~nm})$ were comparable to those shown in the BSE image of Fig. 1b. The coarse particles had two distinct shapes, cubic and nodular, as clearly shown in the STEM image of Fig. 2b. EDS analyses in Fig. 2d indicated that the cubic (P1) and nodular (P2) particles are Cr-rich phase and $\mathrm{Nb}$ /Ti-rich nitride, respectively. The Cr-rich phase might be $\mathrm{M}_{23} \mathrm{C}_{6}$ as suggested by XRD in Fig. 5, although C-peak was not well pick-up in the EDS spectrum. Although the STEM-EDS probe size limit prevented reliable chemical compositions from the ultrafine particles in Fig. 2b, as well as those imaged at a higher magnification in Fig. 2c, the ultrafine particles may be $\mathrm{NbC}$ because of their slight $\mathrm{Nb}$ enrichment. In general, the AR sample had a low dislocation density. Some tangled dislocations, together with some free dislocation segments, were observed in the matrix, which suggests that 
the material did not undergo complete recrystallization after the deformation and annealing processes.
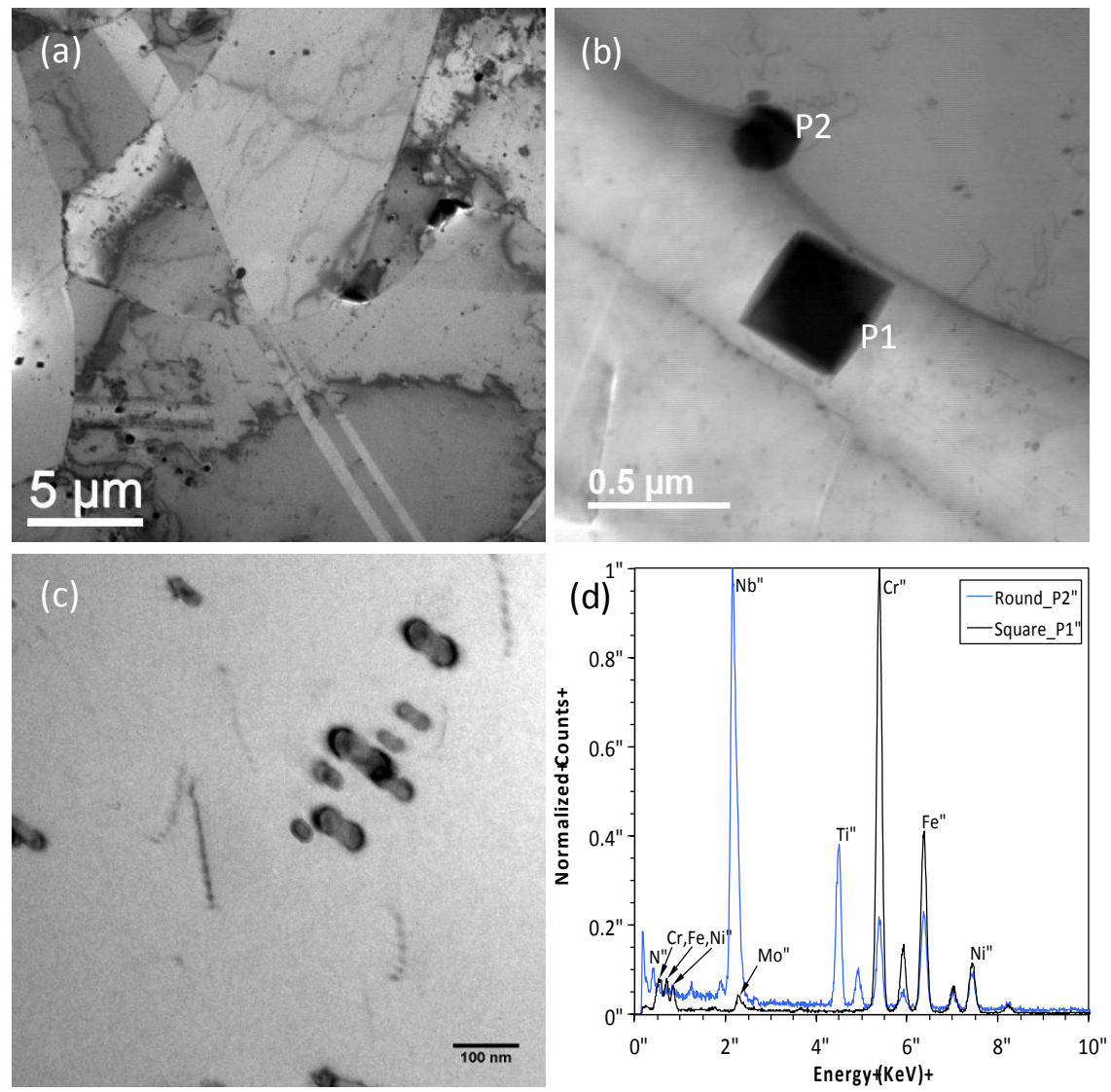

Fig. 2. Microstructure of the AR sample: (a) BF-TEM image overview of grain structure and precipitates, (b) STEM image of coarse and ultrafine precipitates, (c) BF-TEM image of ultrafine precipitates, and (d) STEM-EDS spectra of the precipitates in (b).

\subsection{Irradiated sample $\left(3 \mathrm{dpa} / 500^{\circ} \mathrm{C}\right)$}

Similar to the results for general austenitic stainless steels, the irradiation experiment resulted primarily in the formation of Frank loops. The rel-rod dark-field (DF) imaging technique was employed to characterize Frank loops because of their low contrast in bright-field (BF) images [13]. The [011] zone axis was selected and tiled to a two-beam condition of [311]. The rel-rod streak between the (011) and (200) diffraction spots was selected to form a DF image of Frank loops. Figure 3a shows an example image of Frank loops taken under one of the imaging conditions. Similar images were taken from five different areas. The number and sizes (lengths) of the Frank loops were statistically analyzed and plotted in Fig. 3b. With the successful use of the extreme function to fit the size distribution of Frank loops [14], the function of $y=y_{0}+$ $A \exp [-\exp (-z)-z+1)$-where $z=\left(x-x_{\mathrm{c}}\right) / w$ and $y_{0}, x_{\mathrm{c}}, w$, and $A$ are the profile offset, peak center, width, and amplitude, respectively - was applied to the data in Fig. 3b. It yielded reasonably good fitting results with an adjusted $\mathrm{R}^{2}$ of 0.90 . Frank loops of $\sim 6 \mathrm{~nm}$ appeared dominantly, and loops $>24 \mathrm{~nm}$ were rarely found. Analysis showed the average loop size to be 
$8.2 \pm 5.3 \mathrm{~nm}$, and the loop volume density in all four $\{111\}$ variants was estimated at $(3.27 \pm$ $0.54) \times 10^{22} \mathrm{~m}^{-3}$. Free dislocations (e.g., as in Fig. 2 for the AR sample) were not observed in the $3 \mathrm{dpa} / 500^{\circ} \mathrm{C}$ sample: their absence may be due to the relatively low dose [15].
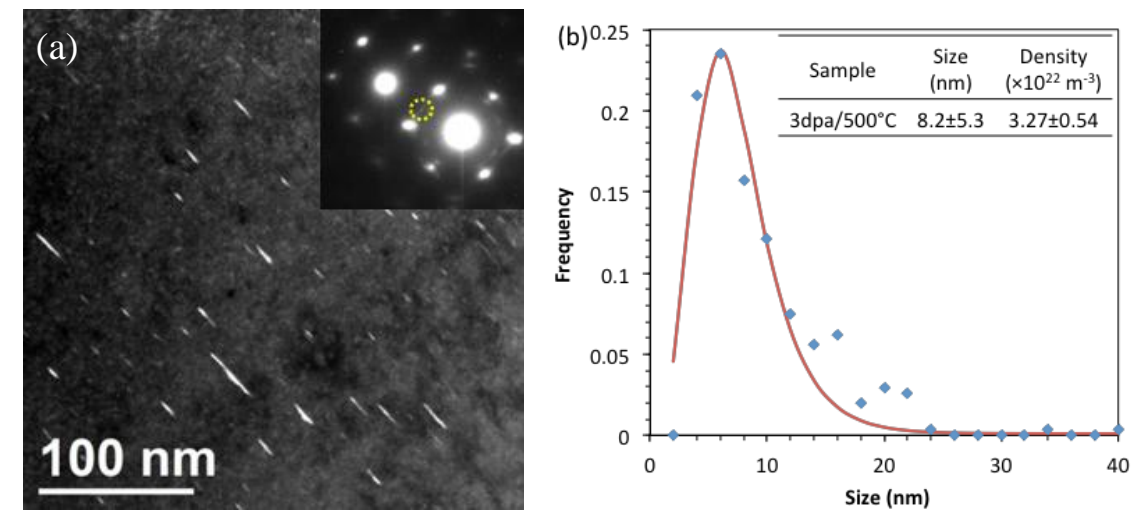

Fig.3 (a) DF image example of Frank loops captured using rel-rod imaging in the inset and (b) statistically analyzed loop size distribution in the $3 \mathrm{dpa} / 500^{\circ} \mathrm{C}$ sample.

Nickel and boron content in alloys are the primary sources of helium production through the reaction of $\left.{ }^{10} \mathrm{~B}(n, \alpha)\right)^{7} \mathrm{Li}$ and the two-step reaction of ${ }^{58} \mathrm{Ni}(n, \gamma){ }^{59} \mathrm{Ni}(n, \alpha){ }^{56} \mathrm{Fe}$ [16]. The gas elements can accumulate into voids, resulting in swelling and property changes [17]. Swelling has shown a strong dependence on nickel content; e.g., minimal swelling in alloys with 30-35 wt \% nickel was observed in studies of $\mathrm{Fe}-15 \mathrm{Cr}-(15-85) \mathrm{Ni}$ ternary alloys that were irradiated in the EBR-II reactor at $510^{\circ} \mathrm{C}$ to various neutron fluences [18]. However, voids were not observed in the $3 \mathrm{dpa} / 500^{\circ} \mathrm{C}$ sample despite the presence of $25.7 \% \mathrm{Ni}$ and $0.0014 \% \mathrm{~B}$ in the alloy. Further study will be pursued and compared with the samples irradiated to the higher dose (6 dpa) at different temperatures to elucidate the void formation tendency of this alloy.

Figure $4 \mathrm{a}$ shows a $\mathrm{BSE}$ image of the $3 \mathrm{dpa} / 500^{\circ} \mathrm{C}$ sample, which indicates a scatter of some dark, fine Ti-rich particles $(\sim 80 \mathrm{~nm})$, together with a few bright fine Nb-rich particles $(\sim 80 \mathrm{~nm})$. Unlike in Fig. 1b, coarse Nb-rich particles were not detected in the irradiated sample. Additionally, the notable increase in Ti-rich particles and decrease in Nb-rich particles per area may suggest the radiation-induced/enhanced formation of Ti-rich particles and the reduction of $\mathrm{Nb}$-rich particles. The near [011] zone axis TEM imaging condition was used to characterize precipitates in the irradiated sample. A singular nanoparticle existing between the annealing twins in Fig. 4b was identified by EDS as Ti-rich carbide, as shown in Fig. 4c. In addition to the Ti-rich carbides, many ultrafine particles $<7 \mathrm{~nm}$ in size were observed in the $3 \mathrm{dpa} / 500^{\circ} \mathrm{C}$ sample. Figure $4 \mathrm{~d}$ shows an example of ultrafine crystalline particles $(\sim 3 \mathrm{~nm})$ with a density on the order of $10^{21} \mathrm{~m}^{-3}$ in a DF image using the encircled reflection in the inset. Although reliable EDS profiles were not obtainable because of the tiny particle size, the results obtained indicated slight $\mathrm{Ni}, \mathrm{Cr}$, and $\mathrm{Cu}$ enrichments of the particles. The ultrafine unknown precipitates may be G-phase particles, according to Refs. [4,5,6], which consumed $\mathrm{Nb}(\mathrm{C}, \mathrm{N})$. An atomic probe study was initiated recently to gain a better understanding of the ultrafine particles that were not observed in the AR sample. 


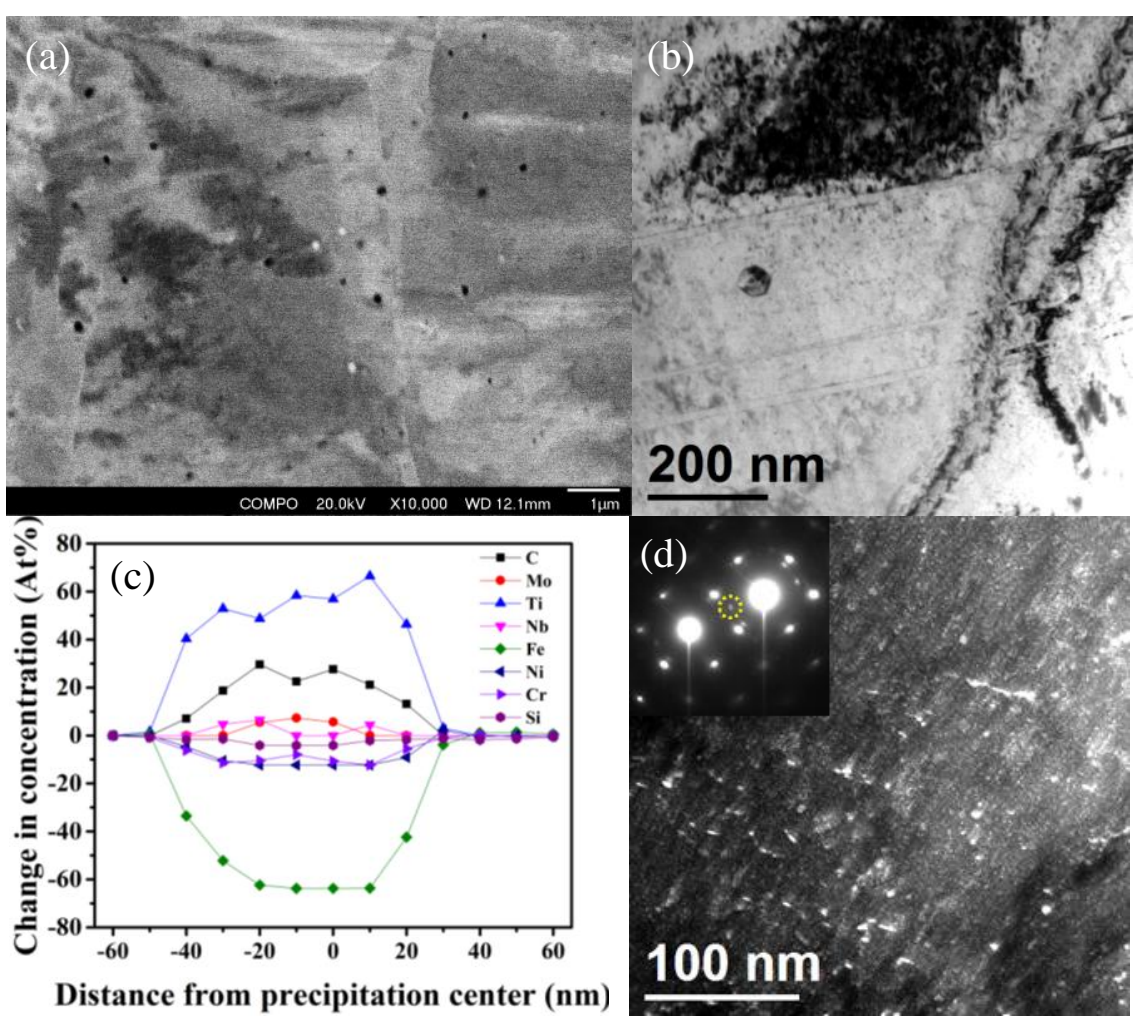

Fig. 4. Precipitates observed in the $3 \mathrm{dpa} / 500^{\circ} \mathrm{C}$ sample: (a) BSE image at $10,000 \times$, (b, c) Ti-rich carbide in the BF TEM image and its EDS elemental profiles, and (d) ultrafine unknown particles.

High-energy XRD was conducted on both the $\mathrm{AR}$ and $3 \mathrm{dpa} / 500^{\circ} \mathrm{C}$ samples. Figure 5 plots the XRD spectra of the two samples with normalized intensity on a logarithmic scale as a function of lattice $d$-spacing. The $3 \mathrm{dpa} / 500^{\circ} \mathrm{C}$ sample showed a higher background than the AR sample, which was mainly attributable to the different experimental conditions (e.g., energy, photon flux, exposure time, detector condition, etc.) during the analyses of the samples in two independent APS sessions. Radiation-induced defects and defect clusters contributed to diffuse scattering signals, leading to potential broadening and shift of Bragg peaks depending upon the radiation damage levels. Two precipitate phases, $\mathrm{M}_{23} \mathrm{C}_{6}$ and $\mathrm{Nb}(\mathrm{C}, \mathrm{N})$, were identified in the $\mathrm{AR}$ sample. The major peaks of the two phases are labeled in Fig. 5. Only very weak peaks of $\mathrm{Nb}(\mathrm{C}, \mathrm{N})$ were observed in the $3 \mathrm{dpa} / 500^{\circ} \mathrm{C}$ sample with the (200) peak at $1.56 \AA$ as an example that has intensity well above the background. The XRD result confirms that $\mathrm{Cr}$-rich precipitates shown in Figs. 1 and 2 are $\mathrm{M}_{23} \mathrm{C}_{6}$ carbides, and $\mathrm{Nb}$-rich particles are $\mathrm{Nb}(\mathrm{C}, \mathrm{N})$. Ti-rich precipitates were not identified in the $\mathrm{AR}$ sample from the $\mathrm{XRD}$ results. Irradiation caused reduction of $\mathrm{M}_{23} \mathrm{C}_{6}$ carbides and significantly reduced the amount of $\mathrm{Nb}(\mathrm{C}, \mathrm{N})$. However, the increased number density of Ti-rich carbides and the newly formed ultrafine unknown particles observed by BES/TEM did not result in the appearance of new peaks in the XRD of the irradiated sample. The amount of phases, e.g., the unknown particles with $\sim 0.005$ vol. $\%$, may be beyond the XRD detection limit. 


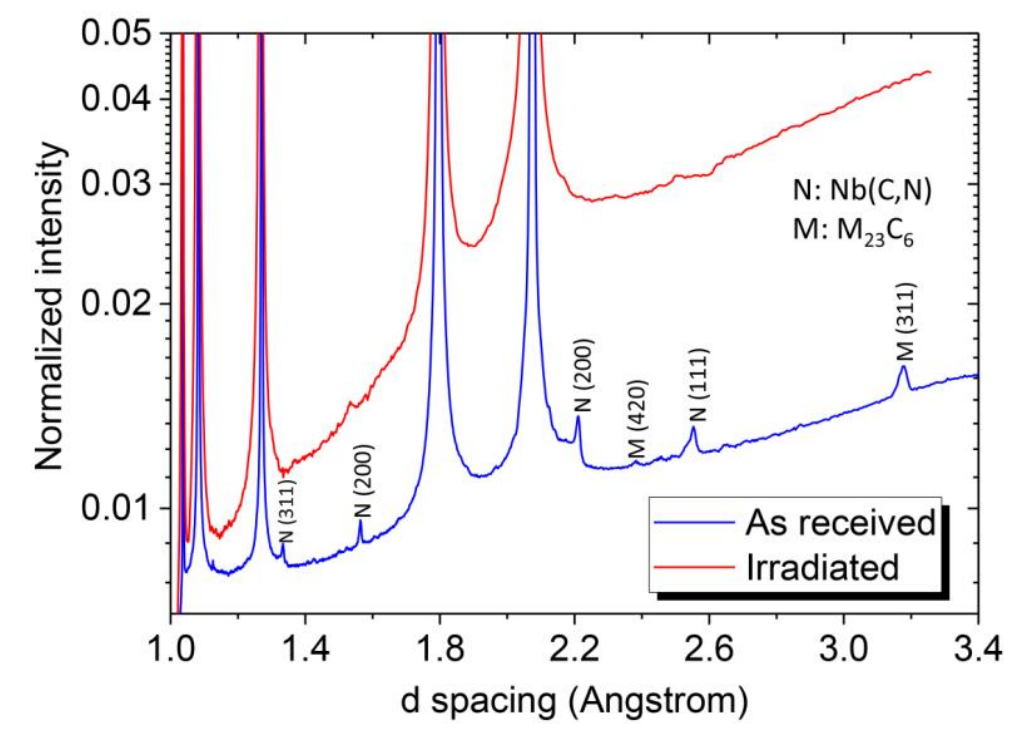

Fig. 5. XRD spectra of the AR (unirradiated) and $3 \mathrm{dpa} / 500^{\circ} \mathrm{C}$ (irradiated) samples.

The observed precipitates in the AR and $3 \mathrm{dpa} / 500^{\circ} \mathrm{C}$ samples are summarized in Table 1 . The suggested precipitates in Table 1 have the primary elemental component listed first in bold font in parentheses. The dominant amount of $(\mathbf{N b}, \mathrm{Ti})(\mathbf{N}, \mathrm{C})$ and $(\mathbf{N b}, \mathrm{Ti})(\mathbf{C}, \mathrm{N})$ precipitates preexisting in the AR sample was significantly reduced by irradiation. The reduction in Nb-rich precipitates may have favored the formation of Ni-rich ultrafine unknown precipitates, possibly G-phase $\mathrm{Ni}_{16} \mathrm{Nb}_{6} \mathrm{Si}_{7}$, during irradiation. Precipitates of $\mathrm{Ti}(\mathrm{C}, \mathrm{N})$ also formed during the irradiation. However, the amounts of the radiation-enhanced or -induced Ni-rich and Ti-rich precipitates were too small to be detected by XRD. The pre-existing $\mathrm{M}_{23} \mathrm{C}_{6}$ may was not observed in the irradiated sample, suggesting radiation-induced phase dissolution or transformation (e.g., [14]). The small amounts of pre-existing $(\mathbf{T i}, \mathrm{Nb})(\mathbf{N}, \mathrm{C})$ particles may have limited their observation in the irradiated sample.

Table 1. Precipitates observed in the $\mathrm{AR}$ and $3 \mathrm{dpa} / 500^{\circ} \mathrm{C}$ samples.

\begin{tabular}{cccc}
\hline Sample & Precipitate & Size, $\mathrm{nm}$ & Identification technique \\
\hline \multirow{3}{*}{ AR } & Nb-rich, e.g., $(\mathbf{N b}, \mathrm{Ti})(\mathbf{N}, \mathrm{C})$ & $400-$ & \multirow{2}{*}{ SEM/EDS/XRD } \\
\cline { 2 - 4 } & Nb-rich, e.g., $(\mathbf{N b}, \mathrm{Ti})(\mathbf{C}, \mathbf{N})$ & $20-1000$ & SEM/TEM/EDS/XRD \\
\cline { 2 - 4 } & Ti-rich, e.g., $(\mathbf{T i}, \mathbf{N b})(\mathbf{N}, \mathrm{C})$ & $<\sim 4,000$ & SEM/EDS \\
\cline { 2 - 4 } & Cr-rich, e.g., $\mathrm{M}_{23} \mathrm{C}_{6}$ & $<\sim 400$ & XRD/TEM/EDS \\
\hline \multirow{3}{*}{$3 \mathrm{dpa} / 500^{\circ} \mathrm{C}$} & Nb-rich, e.g., $(\mathbf{N b}, \mathrm{Ti})(\mathbf{C}, \mathrm{N})$ & $\sim 80$ & SEM/XRD \\
\cline { 2 - 4 } & Ti-rich, e.g., Ti(C,N) & $\sim 80$ & SEM/TEM/EDS \\
\cline { 2 - 4 } & Ni-rich (unknown phase) & $<\sim 7$ & TEM/EDS \\
\hline
\end{tabular}

\subsection{Radiation induced segregation}

RIS was analyzed using STEM-EDS. Figure 6 shows examples of RIS at a general grain boundary and at a dislocation loop. The EDS line-scan locations are schematically marked with 
the dotted lines on the STEM images. The EDS profiles at the grain boundary (Fig. 6a) indicate the enrichment of $\mathrm{Ni}(7.1 \mathrm{wt} \%)$ and $\mathrm{Si}(1.3 \mathrm{wt} \%)$ and the depletion of $\mathrm{Cr}(-3.1 \mathrm{wt} \%)$ and $\mathrm{Fe}(-$ 5.3 wt \%). The grain boundary RIS of $\mathrm{Ni} / \mathrm{Si}$ enrichment and $\mathrm{Cr}$ depletion is similar to that generally observed in irradiated stainless steels. Compared with the Fe-20Cr-24Ni protonirradiated to $0.5 \mathrm{dpa}$ at $500^{\circ} \mathrm{C}$, which exhibited $4.6 \mathrm{wt} \% \mathrm{Ni}$ enrichment and $-11.3 \mathrm{wt} \% \mathrm{Cr}$ depletion [9], the $3 \mathrm{dpa} / 500^{\circ} \mathrm{C}$ NF709 showed similar RIS phenomena but at a different magnitude. The difference may be attributable to the complex alloy composition of NF709, grain boundary types, possible difference in irradiation temperatures, and analytical tools (Auger electron spectroscopy in [9] and TEM in this work). Dislocation loops also showed RIS similar to that at grain boundaries. Figure $6 \mathrm{~b}$ shows EDS profiles of a dislocation loop with the enrichment of $\mathrm{Ni}(6.1 \mathrm{wt} \%)$ and $\mathrm{Si}(1.8 \mathrm{wt} \%)$ and the depletion of $\mathrm{Cr}(-2.1 \mathrm{wt} \%)$ and $\mathrm{Fe}(-5.8$ wt \%). Compared with grain boundaries, the narrower width of the dislocation loop led to a narrower segregation region and a smaller magnitude of segregation. However, the RIS at the dislocation loop had likely been underestimated because of the tiny defect embedded in the matrix. The RIS behavior at dislocation loops was similar to but at smaller segregation levels than that observed in a titanium-modified type 316 stainless steel irradiated in the Fast Flux Test Facility to $15 \mathrm{dpa}$ at $520^{\circ} \mathrm{C}$ [19].
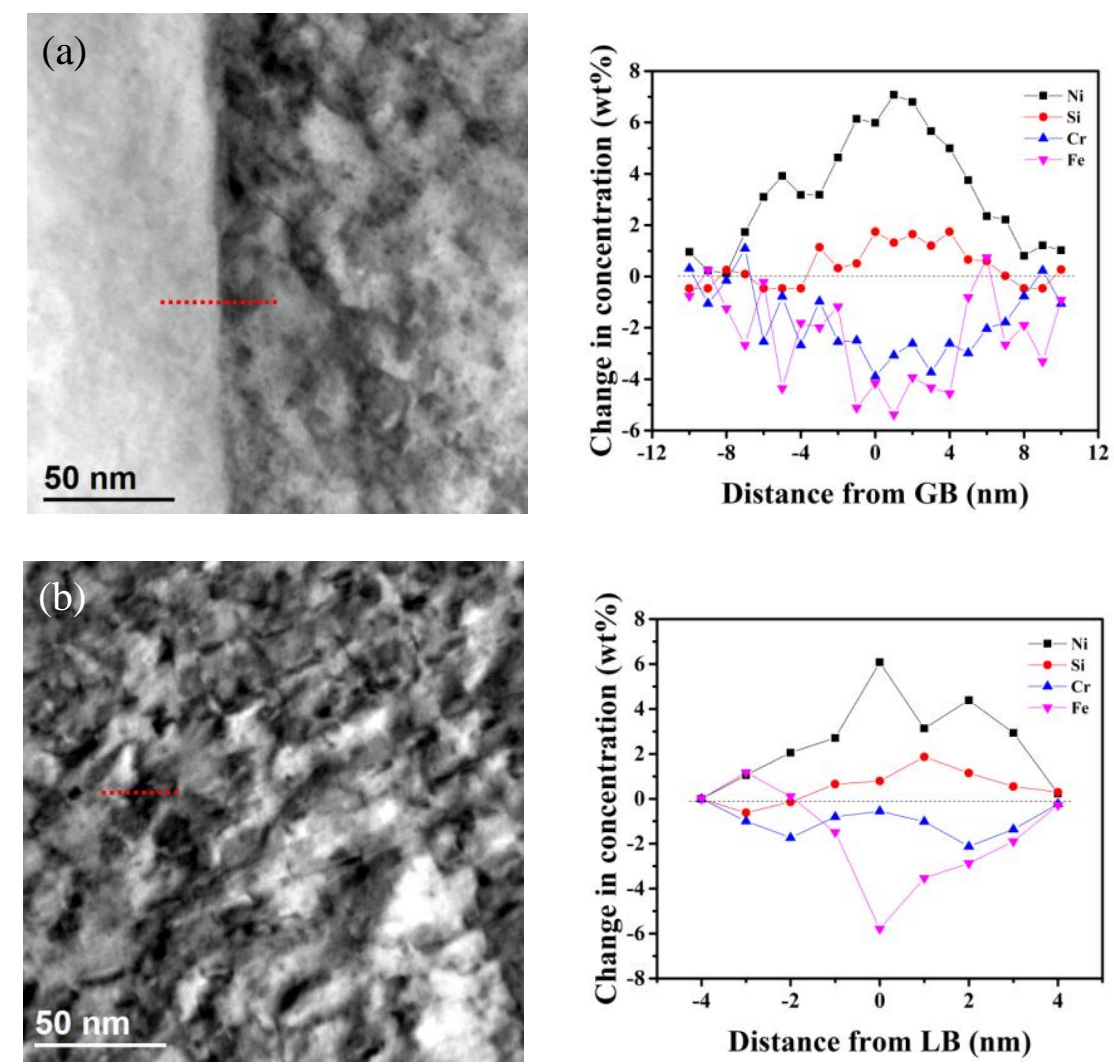

Fig. 6. STEM and EDS profiles showing RIS at (a) grain boundary and (b) at a dislocation loop in the $3 \mathrm{dpa} / 500^{\circ} \mathrm{C}$ sample.

\subsection{Radiation hardening}


Nanoindentation tests were conducted on both the $\mathrm{AR}$ and $3 \mathrm{dpa} / 500^{\circ} \mathrm{C}$ samples. The results indicated the elastic modulus $(E)$ increased from $197.8 \pm 6.6 \mathrm{GPa}$ to $211.94 \pm 9.2 \mathrm{GPa}$ (an $\sim 7.1 \%$ increase) and the hardness increased from $2.94 \mathrm{GPa} \pm 0.14 \mathrm{GPa}$ to $5.16 \pm 0.27 \mathrm{GPa}(\sim 75.5 \%$ hardening). According to the dispersed barrier-hardening model, the radiation hardening $\left(\Delta \sigma_{\mathrm{y}}\right)$ by Frank loops and the unknown precipitates can be estimated by $\Delta \sigma_{y} \approx M \alpha \mu b \sqrt{N d}$, where $M$ is the Taylor factor (3.06 for austenitic stainless steels), $\alpha$ the strength factor, $\mu$ the shear modulus of NF709 ( $\mu \approx E / 2.6$ assuming homogeneous isotropic material), $b$ the magnitude of the Burgers vector $(\sim 0.253 \mathrm{~nm}), N$ and $d$ the number density and size of the loops and particles, respectively. With $\alpha_{\text {Loops }}=0.483$ and $\alpha_{\text {Precipitates }}=0.368$, according to Ref. [20], the hardening induced by the loops and the unknown precipitates can be estimated as 499 and $80 \mathrm{MPa}$, respectively. It corresponds to $506 \mathrm{MPa}$ hardening according to the root-sum-square law (or $579 \mathrm{MPa}$ hardening according to the linear law because of the relatively large different hardening levels). The estimated hardening is comparable to or slightly higher than the yield strength of NF709 and general austenitic stainless steels, which suggests $\sim 100 \%$ hardening. The hardening assessed by measurement $(\sim 75.5 \%)$ is lower than the calculated hardening; that result may be partially attributable to the reduced amount of the pre-existing $\mathrm{Nb}$-rich and $\mathrm{M}_{23} \mathrm{C}_{6}$ particles, which resulted in a reduction in particle strengthening that could not be compensated by the formation of radiation-induced Ti-rich and Ni-rich particles. The noticeable radiation hardening is consistent with findings in Refs. [7,8]. Because of the reductions in shear modulus and strength factor at elevated temperatures as suggested in Ref. [20], the estimated radiation hardening at $500^{\circ} \mathrm{C}$ would be about $370 \mathrm{MPa}$. Radiation hardening is usually accompanied by a ductility loss and fracture mode changes that need to be investigated using the neutron-irradiated tensile specimens.

\section{Conclusions}

The microstructural evolution of NF709 irradiated to $3 \mathrm{dpa}$ at $500^{\circ} \mathrm{C}$, together with that of its archive unirradiated sample, was characterized using SEM, TEM, XRD, and nanoindentation. Similar to findings for general austenitic stainless steels, Frank loops were found to be the primary radiation-induced defects, having an average size of $8.2 \mathrm{~nm}$ and a density of $3.27 \times 10^{22}$ $\mathrm{m}^{-3}$. The amounts of pre-existing coarse and fine $\mathrm{Nb}$-rich precipitates and $\mathrm{M}_{23} \mathrm{C}_{6}$ particles were mostly reduced after irradiation, and their reduction was accompanied by an increased amount of fine Ti-rich precipitates $(\sim 80 \mathrm{~nm})$ and ultrafine Ni-rich unknown precipitates $(\sim 3 \mathrm{~nm}$ size and density on the order of $\left.10^{21} \mathrm{~m}^{-3}\right)$. The amounts of additional and newly formed precipitates did not yield new peaks in the XRD measurement. Nanoindentation measurements suggested $\sim 76 \%$ radiation hardening to $5.16 \mathrm{GPa}$ from $2.94 \mathrm{GPa}$ of the archive sample. The hardening was primarily attributable to Frank loops and somewhat to the unknown precipitates; they were estimated to cause $\sim 499$ and $\sim 80 \mathrm{MPa}$ hardening, respectively, according to the dispersed barrier-hardening model. Noticeable radiation-induced enrichment of $\mathrm{Ni}$ and $\mathrm{Si}$ and depletion of $\mathrm{Cr}$ and Fe were observed at grain boundaries, as well as at dislocation loops, but at a smaller segregation levels. Voids were not observed in the irradiated sample.

\section{Acknowledgments}


This research was sponsored by the US Department of Energy, Office of Nuclear Energy, Nuclear Energy Enabling Technology (NEET) program, under contract DE-AC05-00OR22725 with University of Tennessee-Battelle, LLC. The DOE Office of Nuclear Energy National Scientific User Facility is appreciated for providing the irradiated samples.

\section{References}

[1] S. Kihara, A. Ohtomo, I. Kajigaya, F. Kishimoto, Recent plant experience and research into fireside corrosion in Japan, Werkstoffe und Korrosion, 39 (1988) 69-83.

[2] H. Naoi, H. Mimura, M. Ohgami, M. Sakakibara, S. Araki, Y. Sogoh, T. Ogawa, H. Sakurai, T. Fujita, Development of tubes and pipes for ultra-supercritical thermal power plant boilers, Nippon Steel Technical Report 57 (1993) 22-27.

[3] T. Sourmail, H.K.D.H. Bhadeshia, Microstructural evolution in two variants of NF709 at 1023 and 1073 K, Metall. Mater. Trans. A 36 (2005) 23-34.

[4] R.C. Ecob, R.C. Lobb, V.L. Kohler, The formation of G-phase in $20 / 25 \mathrm{Nb}$ stainless steel AGR fuel cladding alloy and its effect on creep properties, J. Mater. Sci. 22 (1987) 28672880.

[5] D.J. Powell, R. Pilkington, D.A. Miller, The precipitation characteristics of $20 \% \mathrm{Cr} / 25 \% \mathrm{Ni}$ $\mathrm{Nb}$ stabilized stainless steel, Acta Metall. 36 (1988) 713-724.

[6] C. Taylor, Precipitation in $20 \mathrm{Cr}-25 \mathrm{Ni}$ type stainless steel irradiated at low temperatures in a thermal reactor (AGR), in: Dimensional Stability and Mechanical Behaviour of Irradiated Metals and Alloys, British Nuclear Energy Society, London, V. 1, 1983, p. 47-50.

[7] A.N. Hughes, J.R. Caley, Effects of neutron irradiation at elevated temperatures on the tensile properties of some austenitic stainless steels, J. Nucl. Mater. 10 (1963) 60-62.

[8] J.T. Venard, J.R. Weir, In-reactor stress-rupture properties of a $20 \mathrm{Cr}-25 \mathrm{Ni}$, columbiumstabilized steel, in: Flow and Fracture of Metals and Alloys in Nuclear Environments, ASTM STP 380, 1965, p. 269-282.

[9] T.R. Allen, G.S. Was, Modeling radiation-induced segregation in austenitic Fe-Cr-Ni alloys, Acta Mater. 46 (1998) 3679-3691.

[10] M.A. Ashworth, D.I.R. Norris, I.P. Jones, Radiation-induced segregation in Fe-20Cr-25Ni$\mathrm{Nb}$ based austenitic stainless steels, J. Nucl. Mater. 189 (1992) 289-302.

[11] H.J. MacLean, K. Sridharan, T.A. Hyde, Irradiation Test Plan for the ATR National Scientific User Facility-University of Wisconsin Pilot Project, INL/EXT-09-15627, June 2008.

[12] ASTM Designation A213/A213M - 11, Standard specification for seamless ferritic and austenitic alloy-steel boiler, superheater, and heat-exchanger tubes, ASTM International, PA, US.

[13] L. Tan, J.T. Busby, H.J.M. Chichester, K. Sridharan, T.R. Allen, Thermomechanical treatment for improved neutron irradiation resistance of austenitic alloy $(\mathrm{Fe}-21 \mathrm{Ni}-32 \mathrm{Ni}), \mathrm{J}$. Nucl. Mater. 437 (2103) 70-74.

[14] L. Tan, J.T. Busby, Alloying effect of $\mathrm{Ni}$ and $\mathrm{Cr}$ on irradiated microstructural evolution of type 304 stainless steels, J. Nucl. Mater. 443 (2013) 351-358.

[15] R.L. Simons and L.A. Hulbert, Correlation of yield strength with irradiation-induced microstructure in AISI type 316 stainless steel, in: F.A. Garner, J.S. Perrin (eds.), Effects of Radiation on Materials: 12th Int. Symp., ASTM STP 870, 1985, p. 820-839 
[16] G.S. Was, Fundamentals of Radiation Materials Science-Metals and Alloys, SpringerVerlag, Berlin, Heidelberg 2007.

[17] G.E. Lucas, The evolution of mechanical property change in irradiated austenitic stainless steels, J. Nucl. Mater. 206 (1993) 287-305.

[18] T. Muroga, F.A. Garner, S. Ohnuki, Microstructural investigation of swelling dependence on nickel content in fast neutron-irradiated $\mathrm{Fe}-\mathrm{Cr}-\mathrm{Ni}$ austenitic ternaries, J. Nucl. Mater. 179-181 (1991) 546-549.

[19] E.A. Kenik, Elemental inhomogeneities developed in stainless steels by radiation-induced segregation, J. Nucl. Mater. 205 (1993) 317-323.

[20] L. Tan, J.T. Busby, Formulating the strength factor $\alpha$ for improved predictability of radiation hardening, J. Nucl. Mater. 465 (2015) 724-730. 